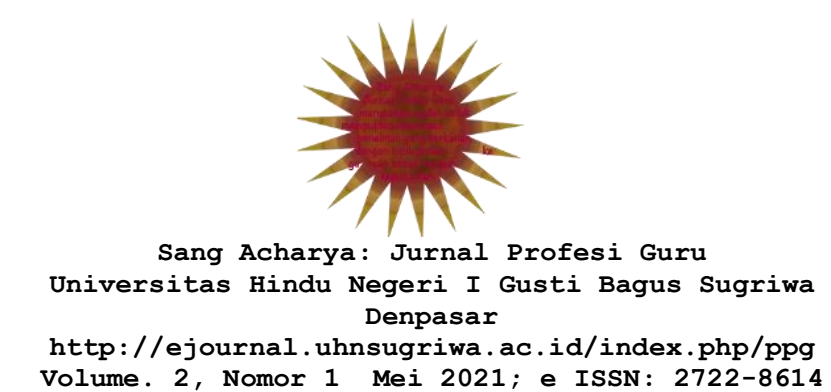

Volume. 2, Nomor 1 Mei 2021; e ISSN: 2722-8614

\title{
HUKUM KARMAPHALA \\ DALAM PANDANGAN TUTUR LEBUR GANGSA \\ (SUATU TELAAH FILSAFAT PRAKTIS)
}

Gusti Ayu Puspa Yanti; Nengah Adi Widiastrawan; I Made Gede Budhyastra

Universitas Hindu Negeri I Gusti Bagus Sugriwa Denpasar

gustiayupuspayanti19@gmail.com; adinengah378@gmail.com;

madebudhyastra96@gmail.com

Diterima 5 April 2021, direvisi 10 April 2021, diterbitkan 1 Mei 2021

\begin{abstract}
Abstrak
Kajian teks Tutur Lebur Gangsa dalam tulisan ini, mempunyai tujuan yang diinginkan sesuai dengan subjektif penulis. Tujuan tersebut diuraikan sebagai berikut. Mendeskripsikan dan memahami suatu uraian dalam Tutur Lebur Gangsa sebagai penggamabaran ajaran Karmaphala dan memahami kegunaan Tutur Lebur Gangsa sebagai referensi tentang pedagogi konvensional yang layak untuk diimplementasikan sampai sekarang. Metode penulisan yang dipergunakan dalam tulisan ini adalah metode interpretasi yang merupakan metode tafsir yang dapat dikaitkan dengan berbagai literaturliteratur lainnya untuk mencari bahasan sesuai dengan kebutuhan kajian ini. dan metode penyajiannya digunakan interpretative-deskriptif. Hasil penelitian ini menunjukkan, bahwa: Teks Tutur Lebur Gangsa menguraikan perihal keadaan manusia di kehidupan ini, seperti mengapa manusia dapat mengalami keadaan baik saat sekarang yang dirasakan sebagai suatu keindahan dan keburukan.
\end{abstract}

Kata kunci: Karmaphala, Tutur Lebur Gangsa

\begin{abstract}
The study of the Tutur Lebur Gangsa text in this paper has the desired objectives in accordance with the author's subjective. These objectives are described as follows. Describe and understand a description in Tutur Lebur Gangsa as a description of Karmaphala teachings and understand the use of Tutur Lebur Gangsa as a reference to conventional pedagogy that is feasible to be implemented until now. The writing method used in this paper is the method of interpretation which is a method of interpretation that can be linked to various other literatures to find a discussion in accordance with the needs of this study. and the method of presentation is used interpretive-descriptive. The results of this study indicate that: The text of Tutur Lebur Gangsa describes the human condition in this life, such as why humans can experience good conditions now that are perceived as beauty and ugliness.
\end{abstract}

Keywords: Karmaphala, Tutur Lebur Gangsa 


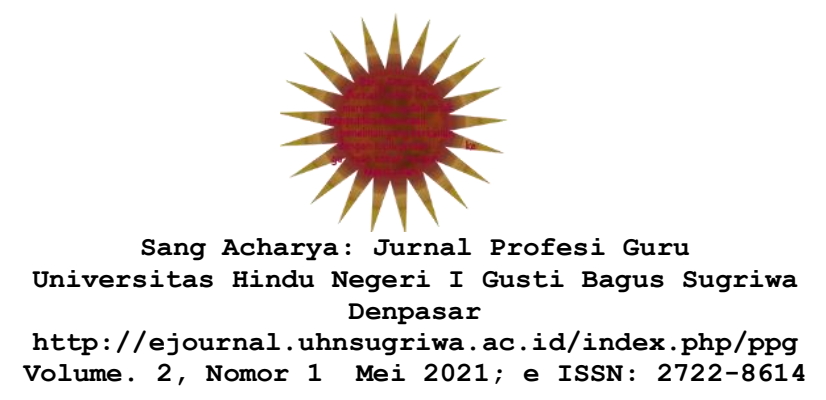

\section{PENDAHULUAN}

Ajaran agama Hindu turtuang dari berbagai hasil karya sastra kuno, baik yang terdapat dalam kitab suci Weda seperti: Sruti, Smerti, Sila, Acara, Atmanastuti dan ribuan lontar, telah menyediakan berbagai kebutuhan-kebutuhan dari aspek yang bermacammacam dari sifat mansusia. Secara ortodoks masyarakat Hindu di Bali dalam memahami ajaran Weda melalui media yang asli budaya nusantara yakni melalui media naskah lontar. Dalam kehidupan masyarakat Bali, lontar mendapatkan tempat yang sangat istimewa. Naskah-naskah lontar yang ada di Bali tersimpang diberbagai tempat, seperti pada instansi ataupun lembaga-lembaga formal yang diantaranya, Gedong Kirtya Singaraja, Dinas Kebudayaan Provinsi Bali, UPT Lontar Fakultas Sastra dan Budaya Udayana, UNHI Denpasar, Universitas Hindu Negeri I Gusti Bagus Sugriwa, Kampus Dwijendra Denpasar, dan masih banyak disimpan pada rumah-rumah penduduk, serta disimpan oleh para pecinta sastra sebagai koleksi pribadi.

Berbagai jenis naskah ataupun teks lontar yang dapat diklarifikasikan, diantaranya berjenis tutur, tattwa, kanda, wariga, babad, dan lain sebagainya. Naskah ataupun teks lontar yang biasanya banyak ditemui adalah yang berjenis tutur dan tattwa. Content dari jenis tutur ini banyak menguraikan tentang dogma agama, filsafat agama, dan bahkan ada yang menguraikan tentang kosmos. Jika diidentifikasi penggunaan bahasanya kebanyakan memakai bahasa Jawa Kuna, ada pula yang memakai bahasa Bali (Agastia, 1994: 6).

Naskah atau teks yang berjenis Tutur merupakan salah satu jenis karya sastra yang mengandung nilai-nilai agama, filsafat dan juga nilai kehidupan. Soebadio menjelaskan tentang arti kata tutur (1985: 3) merupakan pelajaran dogmatis yang diteruskan kepada murid-murid yang memenuhi syarat. Dari segi isinya, karya jenis tutur tidak kalah pentingnya, di dalamnya mengandung nilai-nilai luhur yang sangat erat kaitannya dengan adat-istiadat, hukum adat, upacara keagamaan dan kehidupan sosial lainnya (Sastrawan, 2009: 2). Sesuai dengan uraian tentang tutur tersebut teks lontar Tutur Lebur Gangsa yang memberikan informasi dan pengetahuan yang dapat bermanfaat bagi kehidupan masyararakat khususnya masyarakat Bali, yang mendung nilai-nilai luhur yang mempunyai relasi dengan filsafat keagamaan, upacara keagamaan, serta mengenai kehidupan sosial masyarakat. Selain hal tersebut, Tutur Lebur Gangsa mempunyai fungsi yang terkandung di dalamnya untuk diterapkan dan berkaitan dengan kehidupan religius masyarakat Bali.

Secara keseluruhan teks Tutur Lebur Gangsa, merupakan teks tutur yang menguraikan tentang durmanggala yang artinya tanda atau isyarat yang buruk dan juga disertai tatacara pembersihan perihal tentang kadurmanggalaan. Tanda-tanda atau isyarat tersebut membawa bahaya dalam bentuk kejadian-kejian yang aneh dan tata cara pembersihannya yang diwujudkan menggunakan sarana caru, dan disertai dengan mantra-mantra untuk mengiringinya. Dalam bahasan kajian teks sastra ini, pengamatan difokuskan untuk mengamati secara fenomenologi. Dalam hal ini pengamatan di dasarkan pada aspek apa yang mempengaruhi terjadinya durmanggala, yang ternyata diungkap dalam teks Tutur Lebur Gangsa adalah pengaruh dari Karmaphala. Hukum 


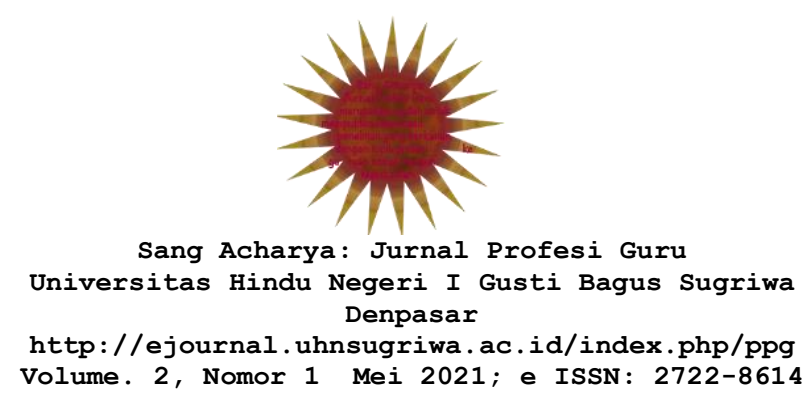

Karmaphala dari kehidupan sebelumnya, sekarang, maupun yang akan datang sangat jelas dijabarkan. Jika ada leluhur yang dahulunya berbuat buruk, akan berdampak buruk pada kehidupannya sekarang, dan semua keturunannya akan bertanggung jawab atas perbuatannya tersebut. Dengan hal tersebut, diberikan juga tatacara untuk membersihakan keadaan tersebut dengan ritual atau upacara yang diungkap dalam pembahasan.

Berdasarkan uraian diatas, keterkaitan dengan kajian teks Tutur Lebur Gangsa penulis mengamati secara fenomenologi tentang ajaran Karmaphala. maka dengan itu dapat ditarik rumusan masalah, Bagaimanakah pandangan Tutur Lebur Gangsa menguraikan tentang hukum Karmaphala?

Kajian teks Tutur Lebur Gangsa dalam tulisan ini, mempunyai tujuan yang diinginkan sesuai dengan subjektif penulis. Tujuan tersebut diuraikan sebagai berikut; (1) Mendeskripsikan dan memahami suatu uraian dalam Tutur Lebur Gangsa sebagai penggamabaran ajaran Karmaphala, (2) Memahami kegunaan Tutur Lebur Gangsa sebagai referensi tentang pedagogi konvensional yang layak untuk diimplementasikan sampai sekarang.

\section{METODE PENULISAN}

Pengkajian dalam teks atau karya sastra diperlukan suatu metode, dengan maksud sebagai alat yang dapat digunakan untuk memahami, dan menguraikan isi (content) dari karya sastra Tutur Lebur Gangsa. Metode yang digunakan dalam kajian ini bukanlah Filologi yang mengutamakan naskah dari segi yang original atau naskah yang memang pertama kali muncul sebagai naskah yang asli atau mendekati keasliannya, tetapi digunakan metode interpretasi yang merupakan metode tafsir yang dapat dikaitkan dengan berbagai literatur-literatur lainnya untuk mencari bahasan sesuai dengan kebutuhan kajian ini. dan metode penyajiannya digunakan interpretative-deskriptif.

\section{PEMBAHASAN}

\subsection{Kodikologi teks Tutur Lebur Gangsa}

Berdasarkan uraian metode pengkajian di atas, dalam bahasan kajian ini tidak menggunakan metode filologi, tetapi digunakan metode interpretasi. Teks Tutur Lebur Gangsa ini adalah suatu naskah yang penulis dapatkan dari Pusat Dokumentasi (PUSDOK) Dinas Kebudayaan Provinsi Bali, sebagai naskah yang penulis gunakan teks di dalamnya sebagai objek kajian dalam tulisan ini. Terkait dengan kodikologi teks Tutur Lebur Gangsa ini diuraikan aspek bahasan mengenai ringkasan teks dan tema teks, untuk memahami kejelasan dari teks Tutur Lebur Gangsa. Perlu diingatkan bahwa teks ini bukan berbentuk narasi cerita, yang menguraikan tentang penokohan, alur, setting, dan lain sebagainya seperti teks yang menguraikan cerita di dalamnya. Adapun aspek bahasan dalam sub bab ini adalah sebagai berikut. 


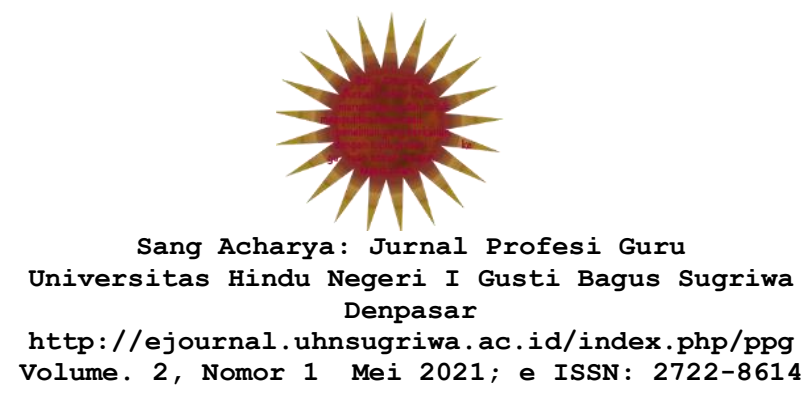

\section{Ringkasan Teks Tutur Lebur Gangsa}

Manusia hendaknya hidup berpedoman sesuai dengan ajaran agama dan tata aturan yang berlaku. Apabila manusia berbuat di luar tata aturan dan berperilaku tidak baik, manusia akan mendapatkan mala petaka yang diciptakan oleh Sang Hyang Lebur Gangsa. Hukum Karmaphala dari kehidupan sebelunya, sekarang maupun yang akan datang. Diuraikan juga bahwa jika leluhur yang dulunya berbuat buruk, akan berdampak buruk pada kehidupannya sekarang, dan semua keturunannya akan bertanggung jawab atas perbuatan tersebut. Begitupula pada kehidupan sekarang, salah satunya jika ada seseorang dukun yang mengobati tidak berdasarkan aturan pengobatan, raganya akan menjadi rumah dari segala penyakit. Hal tersebut disebabkan karena lahir membawa mala dan lahir mendapatkan hukuman. Untuk dapat kembali ke dalam kehidupan yang baik ada suatu upacara yang harus dilaksanakan guna mengembalikan hal seperti itu diharapkan menjadi lebih baik, dengan melaksankan upacara peruatan yang disebut Sasakapan Hala Pati. Pada bagian ini jelas dipaparkan bagimana tata cara dan sesaji yang harus digunakan dan dipersiapkan untuk melaksanakan upacara Sasakapan Hala Pati tersebut.

Selain tentang perihal peruatan seperti yang disebutkan di atas, juga dijelaskan tentang bagaimana ciri-ciri Durmanggala dan Durbhiksa yang terjadi pada alam dan pekarangan rumah. Dijelaskan beberapa tata cara membangun rumah agar terhindar dari malapetaka. Bila ciri-ciri Durmanggala dan Durbhiksa telah tampak, sepatutnya mendirikan tempat suci yang disebut Antasana sebagai stana Sang Hyang Tiga Wisesa yaitu: Sang Hyang Indra belaka, Sang Hyang Durgha Maya, dan Sang Kala Maya. Beliau menunggal mengeluarkan kehebatan menjadi Durga Manik. Jika beliau tidak dibuatkan stana, maka beliau akan memberikan penyakit (kesengsaraan). Dan diuraikan juga terkait bagaimana cara menetralisir dan meruat keangkeran atau pekarangan yang panas dengan upacara mecaru.

\section{Tema Teks Tutur Lebur Gangsa}

Tema merupakan suatu persoalan pokok atau pokok pikiran yang menajdi dasar cerita. Dalam teks Tutur Lebur Gangsa yang menjadi pokok pikiran atau tema adalah Pengruatan (pembersihan) seperti yang dapat dijelaskan bahwa karya sastra ini membicarakan tentang bagaimana tata aturan menjadi manusia dan menjalani hidup sebagai manusia yang dikenal dengan Hukum Karmaphala. selain itu juga membicarakan mengenai bagaimana ciri-ciri atau pertanda buruk serta sebab akibat terhadap suatu tempat atau pekarangan rumah menjadi angker. Kemudian dijelaskan bagaimana cara menetralisir dan mencegah terjadinya hal tersebut karena dapat membahayakan hidup manusia.

\subsection{Pandangan Teks Tutur Lebur Gangsa Tentang Ajaran Karmaphala}

Ajaran agama Hindu, secara teologis memiliki konsep fundamental yang dipahami sebagai landasan berkeyakinan. Keyakinan dalam Hindu berterminologi Sradha. Landasan sradha ini yang menunjukkan bahwa agama Hindu meyakini suatu konseptual yang universal, sebagai pandangan untuk beragama. Pada dasarnya konsep ini 


\section{清 \\ Sang Acharya: Jurnal Profesi Guru \\ Universitas Hindu Negeri I Gusti Bagus Sugriwa \\ Denpasar \\ http://ejournal. uhnsugriwa.ac.id/index.php/ppg \\ Volume. 2, Nomor 1 Mei 2021; e ISSN: 2722-8614}

mempunyai lima pilar yang disebut sebagai Panca Sradha yang terdiri atas, a) Bhaman, b)Atman, c) Karmaphala, d) Punarbawa dan Samsara, dan e) Moksa. Kelima pilar tersebut merupakan dasar umat untuk "yakin" sesuai ajaran agama Hindu. Berdasarkan fokus dalam kajian teks ini yang membahas ajaran Karmaphala sebagai salah satu landasan berkeyakinan umat Hindu. Karmaphala artinya hasil perbuatan yang dilakukan oleh seseorang. Apa yang dikerjakan, baik atau buruk, maka itulah yang dinikmatinya dalam kehidupan ini maupun kelak di kemudian hari sampai di alam niskala (Subagiasta, 2007: 27). Penjelasannya Karmaphala mempunyai beberapa konsep untuk dapat mengetahui pembagiannya secara rinci, yang di dalamnya termuat tiga komponen dalam hal memahaminya.

1. Sancita Karmapala yaitu hasil yang diterima pada kehidupan sekarang atas perbuatannya pada kehidupan sebelumnya.

2. Prarabdha Karmapala yaitu perbuatan yang dilakukan pada kehidupan saat ini dan hasil atau pala nya akan diterima pada kehidupan saat ini juga.

3. Kryamana Karmapala yaitu perbuatan yang dilakukan pada kehidupan saat ini, namun hasilnya akan dinikmati pada kehidupan yang akan datang.

Berdasarkan uraian dalam penjelasan tentang Karmaphala tersebut sebagai pengetahuan dalam memahami uraian ajaran karmaphla menurut teks Tutur Lebur Gangsa. Seperti uraian Karmaphala yang dijelaskan oleh Subagiasta (2007) bahwa manusia dalam kehidupannya akan selalu berbuat (karma) dan juga akan mendapatkan hasilnya (Phala) baik perbuatan yang baik dan buruk akan tetap mendapatkan hasilnya seperti itu. Berdasarkan telaah dalam Tutur Lebur Gangsa, dikarenakan teks ini membahas tentang pengruatan atau pembersihan, maka dijelaskan mengenai karmakarma buruk yang pernah dilakukan, sehingga mendapatkan hasil (Phala) yang sama. Berdasarkan pembagian konsep ajaran Karmaphala di atas dalam teks Tutur Lebur Gangsa, pertama dimulai dengan Sancita Karmaphala, seperti uraian teks di bawah ini.

Bisukali manca, kilanden, tuli, pepengan, saroja, samangkana gendhaning wong sane salah kaluhurane nguni, karana mabekel lara tumitisnya, kringin bulakrik, ebuh, busung, doyog, kalimanca, lakeng banu, tuli, kepes, udug basur, latek, cekeli, kejer, mati wala, nujali, kepekih, kahangan, tan paputra, bleh bangran, salah pati, hedan, ika sami jadma gring tumuwuh, amakta mala, amakta dhandha dumadi.

Terjemahan:

Bisu, tuli, uring-uringan, saroja, demikianlah hukuman yang diterima karena tidak susila dahulunya, itu pula yang menjadi sebab kelahirannya, berbekal derita bulakrik (bulai), krengen (korengan), berpenyakit busung, jalan tidak normal, beri-beri, tuli, krempeng, buah pikirnya besar, cebol, kejang-kejang, mati muda, jamuran, tidak mempunyai keturunan atau tidak bisa mempunyai anak, mati tidak benar, gila, itu semua adalah penyakit karena lahir membawa mala, lahir karena mendapatkan hukuman.

Kutipan teks Tutur Lebur Gangsa di atas menjelaskan perihal hukuman yang di dapat diterima oleh manusia setelah kelahirannya, jika mempunyai ciri-ciri seperti yang 


\section{$\frac{1}{3} \frac{1}{11}$ \\ Sang Acharya: Jurnal Profesi Guru \\ Universitas Hindu Negeri I Gusti Bagus Sugriwa Denpasar \\ http://ejournal. uhnsugriwa.ac.id/index.php/ppg \\ Volume. 2, Nomor 1 Mei 2021; e ISSN: 2722-8614}

diuraikan, bisu, tuli, korengan, krempeng, beri-beri, dan lain sebaginya merupakan pertanda bahwa kehidupan terhadulunya menyimpan perbuatan (karma) yang amat tidak sesuai dengan norma, moral, dan ajaran agama, sehingga mendapatkan hukuman (Phala) dalam kehidupan selanjutnya secara ekplisit uraian di atas menunjukkan tentang apa yang disebut sebagai Sancita Karmaphla_yang mana menjelaskan tentang Phala (hasil) dari perbuatan (Karma) yang dilaksanakan dalam kehidupan sebelumnya. Dalam teks Agastya Parwa, menyatakan bahwa roh dalam proses evolusinya hingga dapat menyatu kembali dengan Sang Maha Roh (Brahman), haruslah melalui proses peningkatan kelahiran, dari yang rendah menuju proses kelahiran yang lebih tinggi. Roh terendah akan lahir dalam wujud berbagai jenis tamanan (odwad, wrksa, wanaspati, dll) jika beruntung roh tanaman akan menjelma menjadi berbagai jenis binatang, dan jika beruntung lagi roh binatang akan menjelma menjadi manusia; dari wujud manusia berdasar kemampuan berfikirnya paling tidak menjadi dewata (Aryana, 2008: 25). Terkait dengan apa yang di uraikan oleh Aryana yang sebagaimana dikutip dari teks Agastya Parwa, setiap roh akan mengalami proses evolusi menjadi lebih baik, dengan demikian setiap roh akan mengalami proses tersebut sesuai dengan karma yang pernah dilakukan, sehingga hukum karmaphala berjalan sesuai dengan sistem yang ada. Selanjutnya dibahas mengenai komponen yang kedua Prarabdha Karmaphala, sesuai dengan uraian berikut.

Angku-aku dewa, angku-aku pitara, angrepata tani pedas saking agamaning usaddha, cendet tuwuh, satekan sahenahnya, anemu sasar mwang mangkana, Bhatara Dewa manendha ya, mwang kala manendha ya apan kasaluk dening bhuta kakrettan, dudu wong mangkana, nora manganggo sepat usaddha, mangaran dudukun, mangundang gendha, kalebu pati. Yaning wong mangleyak, handesti, aneluhi, anerangjana, anyetik, angracun, amateni wong tan padosa, nilib patining wong samanya. Yanya ngada-ada, gendha karubaning langit, yaning balu kaambil taruna yaning taruna ngalap balu. Yaning balu padha balu gendha para temah anusup tekeng luha lubu amilara, tan sah amakta prakara, tumus tekaning awaknya, satata amanggih sangkala, kala dengen manglingse dadi leyak, maroda dadi desti. Yanya wong taruna tuha, anak luh deha tuha, padha banget laranya, ne lanang sekadi gunung laranya, ne wadon sagara laranya.

Terjemahan:

Apabila ada orang yang mengaku-ngaku Dewa, mengaku-ngaku leluhur, berkatakata tidak jelas, tidak berdasarkan ajaran usada, orang yang demikian pendek umurnya. Datang dan perginya mendapat celaka. Bhatara dan dewa mengukumnya. Kala pun menyiksanya, ia dirasuki oleh bhuta kakretan. Bukan manusia namanya orang demikian. Balian (dukun) yang tidak berpedoman kepada usada disebut dudukun. Menanggung dosa, terjerumus dijurang kematian. Apabila ada orang menjadi leak, men-desti, me-neluh, melaksanakan ilmu hitam terangjana, men-cetik, meracun, membunuh orang tanpa dosa, membunuh orang tanpa alasan yang jelas, menjadi pengacau, mencari-cari kesalahan orang, membunuh orang secara misterius, suka mengada-ada, mendapat hukuman karubabaning langit. Apabila janda diambil jejaka, jejaka 


\section{清 \\ Sang Acharya: Jurnal Profesi Guru \\ Universitas Hindu Negeri I Gusti Bagus Sugriwa \\ Denpasar \\ http://ejournal. uhnsugriwa.ac.id/index.php/ppg \\ Volume. 2, Nomor 1 Mei 2021; e ISSN: 2722-8614}

diambil janda, janda kawin dengan duda, dihukum oleh masyarakat. kutukkannya menyusup, sampahpun ikut membencanai, selalu membawa masalah yang menghujani dirinya. Selalu mendapat celaka, Kala Dengen merasuki dirinya dan menjadi leak, dan membencanainya menjadi desti. Apabila perjaka tua, gadis tua, sama-sama menderita sakit keras, yang laki-laki akan seperti gunung berat penyakitnya dan yang perempuan akan seperti lautan berat sakitnya.

Berdasarkan uraian teks di atas terkait dengan Prarabda Karmaphala, dalam proses kehidupan ini, semua atas hasil perbuatan buruk yang dilakukan hasilnya didapatkan pada kehidupan sekarang ini, tanpa menunggu kehidupan yang akan datang. Pada kutipan tersebut dijelaskan pula karma (perbuatan) buruk manusia yang membuat mereka menerima pahala yang buruk pula, hingga Dewa dan Bhuta pun ikut menghukum manusia tersebut karena perbuatannya yang penuh dosa. Terkait dengan konsep Karmaphala yang terakhir yaitu Kriyamana Karmaphala dijelaskan dalam uraian teks berikut.

Yanya wong wadon lobha maring wong lanang, yanya nglesin lakinya amegat tresna, yanya manadi manusa, tumitisnya manadi asu wadon, kapastu dening Bhatara Guru, katemah dening guru, mwang babu pitara, mwang mangkana aninggalin somahnya, dudu ya wong, kudu ya maurip, tan wruh maring dhandha kajatiyan, nora wruh maring kapatiyani, wruh ya mangan juga, karana samangkana, apan ya kena upadrawa, katemah dening Sang Hyang Guru, mwah babu pitara, keni sapaning dewa, yan katekaning pati mwang mangkana, atmanya kalebok ring tanah, buat sasarnya, tan saya, rigetaning mala, papa klesa, dursila, tekaning patinya, sasar buat ya saka ring mati bingung, dadya salah ton, salah ujar, dadi salah paksa, salah palakunya kasalub dening bhuta dengen.

Terjemahan:

Apabila perempuan doyan lelaki, gampang putus cinta, menceraikan lelakinya, penjelmaannya nanti menjadi anjing betina, karena dikutuk oleh Bhatara Guru, dikutuk oleh guru dan leluhurnya. Ia bukan manusia namanya yang dengan tingkah laku demikian meninggalkan suaminya. Percuma ia hidup, tidak tahu hukum kebenaran. Tidak tahu hakekat kematian, tahunya hanya makan saja. Oleh karena itu ia dikutuk oleh Bhatara Guru, leluhurnya dan dikutuk oleh Dewa. Bila ajalnya tiba, rohnya dijerumuskan ke dalam tanah. Sangat berat deritanya. Tidak putus-putusnya dirundung malang, dosa papa. Tanpa susila sampai ajalnya tiba. Kelewat tersesat, kebingungan sampai di alam kematian. Karena dirasuki oleh Bhuta Dengen, ia menjadi salah lihat, salah ucap, salah keyakinan, salah laku

Semua perbuatan buruk yang dilakukan akan berakibat buruk pada kehidupan selanjutnya dan berdampak buruk pula dari sisi penjelmaan ataupun kelahirannya kembali. Dalam uraian kutipan di atas akibat dari perbuatannya yang suka bermain lelaki, maka kelahirannya nanti bukan sebagai manusia, namun sebagai anjing betina. Uraian dari ketiga konsep Karmaphala tersebut dapat disimpulkan bahwa Karmaphala bisa terjadi kapan dan kepada siapa saja karena telah merupakan prinsip semesta (Rta), dengan 


\section{$\frac{1}{3} \frac{1}{11}$ \\ Sang Acharya: Jurnal Profesi Guru \\ Universitas Hindu Negeri I Gusti Bagus Sugriwa Denpasar \\ http://ejournal. uhnsugriwa.ac.id/index.php/ppg \\ Volume. 2, Nomor 1 Mei 2021; e ISSN: 2722-8614}

demikian manusia sudah sepatutnya untuk menjalankan kehidupan sesuai dengan ajaran agama yang baik dan benar. Secara praktis uraian tentang Karmaphala di atas menunjukkan berbagai implikasi yang diperoleh sesuai dengan perbuatan yang pernah dilakukkan sebagai karma, dan tentu mengajarkan kepada manusia untuk dapat bertingkah laku dan berbuat sebagaimana norma dan ajaran dari agama masing-masing.

Orientasi tentang ajaran Karmaphala sesungguhnya memberikan dampak yang akan membentuk moral setiap individu. Dengan adanya pengetahuan terkait dengan Karmaphala setiap orang atau suatu kolektif (masyarakat) dapat mempelajari dan mengajari agar dapat berprilaku baik dalam kehidupannya, karena apapun yang diperbuat maka diterima hasil dari perbuatannya tersebut. Kembali diuraikan dalam teks Tutur Lebur Gangsa, mengajarkan pengetahuan tentang sebab-akibat dengan berbagai contoh perbuatan yang akan berimplikasi teradap kehidupannya, seperti perbuatan buruk yang dominan dilakukan oleh manusia namun tidak disadari bahwa perbuatannya tersebut berdampak buruk terhadap dirinya sendiri. Seperti ungkapan teks di bawah ini.

Yan wong baneh langkung maring sabda makuma bhisa, tan pakoning anake wruh, dhandha swarannya, ya manadi bega tumitisnya. Yaning balian tanpa usaddha, gong dhandhanya pati, kurang awak gendha karubhaya, tarukaning bhaya. Yanya wong wadon lobha maring wong lanang, yanya nglesin lakinya amegat tresna, yanya manadi manusa, tumitisnya manadi asu wadon.

Terjemahan:

Apabila ada orang yang berkata berlebihan, selalu menganggap dirinya bisa, sok tahu, dihukum karena kata-katanya, kelahirannya nanti menjadi orang bisu. Apabila ada balian mengobati tanpa berdasarkan usada, berat hukumnya. Kelahirannya menjadi orang lemah, badannya menjadi perkampungan segala jenis penyakit. Apabila perempuan doyan lelaki, gampang memutuskan cinta, menceraikan lelakinya, kelahirannya kembali menjadi anjing betina.

Uraian dari kutipan teks tersebut memberikan pengajaran dan bahkan untuk mengingatkan banyak personal (masyarakat) bahwa dalam kehidupan tetap berada dalam aturan norma ataupun moral agama. Dengan memperhatikan teks Tutur Lebur Gangsa seperti kutipan di atas. Justru memberikan suatu kewaspadaan tersendiri bagi masyarakat, yang pada inti dari kalimat tersebut mendeskripsikan bagaimana hasil dari perbuatan yang telah dilakukan, jika perbuatan yang dilakukan menunjukkan keburukan, maka hasil yang diterima buruk juga, dan begitu juga sebaliknya. Agar lebih meyakinkan dan agar manusia tetap berperilaku baik dalam kehidupan sehari-hari, berikut diuraikan terkait dengan kutipan teks Tutur Lebur Gangsa yang tidak hanya menjelaskan hasil perbuatan manusia yang berdampak pada perubahan fisik saat kelahirannya kembali namun akan berbekal penyakit atau cacat pada kelahiran berikutnya.

Yanya akeh kang salahnya, kakinon de Sang Hyang Yama manglebok, dangan kalawan habot kagantungan mala, apan ya jadma sami masurat. Bisukali manca, kilanden, tuli, pepengan, saroja, samangkana gendhaning wong sane salah 


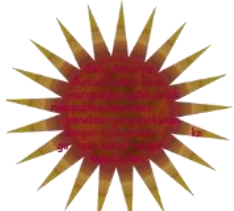 \\ Sang Acharya: Jurnal Profesi Guru \\ Universitas Hindu Negeri I Gusti Bagus Sugriwa Denpasar \\ http://ejournal.uhnsugriwa.ac.id/index.php/ppg \\ Volume. 2, Nomor 1 Mei 2021; e ISSN: 2722-8614}

kaluhurane nguni, karana mebekel lara tumitisnya, kringin bulakrik, ebuh, busung, doyog, kalimanca, lakeng banu, tuli, kepes, hudug basur, latek, cekel, kejer, mati wala, nujali, kapekih, kahangan, tanpa putra, bleh bangran, salah pati, edan, ika sami jadma gring tumuwuh, amakta mala, amakta dhandha dumadi.

Terjemahan:

Apabila kesalahannya banyak, dititahkan oleh Sang Hyang Yama untuk menceburkannya ke Neraka. Berat ataupun ringan dosa-dosanya, sama-sama digantungi hukuman, sebab semua itu sudah tersurat. Bisu, tuli, uring-uringan, demikianlah hukuman yang diterima karena tidak susila, itu pula yang menjadi penyebab kelahirannya berbekal derita bulakrik (bulai), krengen (korengan), berpenyakit busung, jalan tidak normal, beri-beri, tuli, krempeng, buah pikirnya besar, cebol, kejang-kejang, mati muda, jamuran, tidak mempunyai keturunan atau tidak bisa mempunyai anak, mati tidak wajar, gila. Itu semua adalah penyakit karena lahir membawa mala, lahir karena mendapat hukuman.

Diuraikan di atas berdasarkan kutipan tersebut dijelaskan bagaimana akibat yang ditimbulkan karena tidak bersusila, yang dapat berimplikasi bahwa sang Atma akan diberi hukuman untuk kehidupan selanjutnya. Dalam hal ini hukuman tersebut berupa penyakit yang sifatnya membuat kelahiran sang Atma yang menjadi manusia yang cacat atau mempunyai kelainan dari manusia normal. Dengan adanya pengetahuan tentang Karmaphala, secara tidak langsung merupakan hal yang praktis untuk diimplementasikan dalam kehidupannya sehari-hari sesuai dengan adat tradisi, agama dan budaya yang sudah kita miliki.

Dalam proses reinkarnasi yang dalam Hindu lebih dikenal dengan istilah Punarbhawa, merupakan siklus alamiah roh dalam proses evolusinya. Penggambaran Punarbhawa ini dapat diandaikan seperti roda kendaraan yang dilekati oleh lumpur dalam putarannya (Aryana, 2008: 50). Roda kendaraan yang berputar diandaikan sebagai siklus Punarbhawa, sedangkan lumpur-lumpur yang melekat pada roda kendaraan di umpamakan sebagai para roh yang terjebak dalam siklus kelahiran dan kematian yang terus berlanjut. Lumpur yang terjebak pada sisi paling luar dari roda kendaraan tentu dapat dengan cepat terlepas dari putaran roda kendaraan, dibandingkan dengan lumpur yang terjebak di bagian lebih dalam. Demikian juga roh yang presentase kelekatannya lebih sedikit dapat lebih mudah untuk lepas dari siklus punarbhawa dan tidak demikian halnya dengan roh yang memiliki kemelekatan lebih kuat, tentu mereka sangat sulit untuk memperoleh kebebasannya.

Pada kenyataannya roh-roh yang mengalami kesengsaraan lahir-mati, sesungguhnya memiliki kesempatan untuk bergerak naik dan berada pada putaran roda lebih luar, demikian juga ia dapat mengalami kemerosotan hingga memasuki putaran yang paling dalam. Peningkatan kemerosotan roh sesungguhnya disebabkan oleh 'perilaku' yang dalam Hindu disebut sebagai Karma, yang mereka lakukan sendiri dalam wujud dari hasil karmanya. 


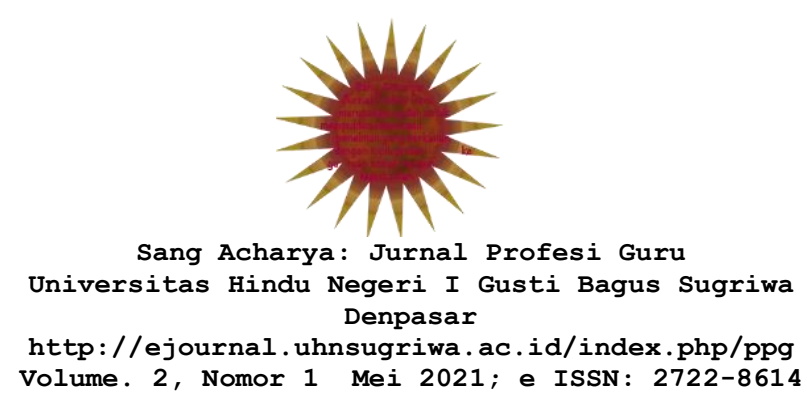

\section{Simpulan}

Berdasarkan hasil pembahasan yang telah diuraikan pada bab sebelumnya. Teks Tutur Lebur Gangsa menguraikan perihal keadaan manusia di kehidupan ini, seperti mengapa manusia dapat mengalami keadaan baik saat sekarang yang dirasakan sebagai suatu keindahan dan keburukan. Menurut teks Tutur Lebur Gangsa hal tersebut tidak lain merupakan hasil (Phala) dari perbuatan (Karma) nya sendiri. Mengingat dalam teks tersebut diuraikan tentang Sancita Karmaphala, Prarabdha Karmaphala, dan Kriyamana Karmaphala, dengan dijelaskan secara ekplisit tentang akibat-akibat yang diperoleh dari perbuatan yang dilakukan manusia. Dalam bahasan selanjutnya diuraikan juga perihal ritual ruwatan untuk dapat membersihakan secara rohani dengan harapan dikehidupan selanjutnya diperoleh suatu yang membahagiaan. Maka yang terakhir dapat dinyatakan bahwa, setiap sastra-sastra atau teks keagamaan, tujuannya adalah memberikan refrensi terhadap umatnya agar dapat mencapai kesempurnaan dan kebahagiaan hidup.

\section{DAFTAR PUSTAKA}

Alih Aksara Lontar Tutur Lebur Gangsa, 2000,Dinas Kebudayaan Provinsi Bali

Agastia, Ida Bagus. 1994. Kesusastraan Hindu Indonesia. Denpasar: Yayasan Dharma Sastra.

Aryana, IB Putra Manik. 2008. Atma Prasangsa: Memahami Kematian dalam Tradisi Budaya Bali. Denpasar: Bali Aga.

Sastrawan, I Made Anom. 2009. Tutur Panugrahan Dalem, Analisis Struktur dan Fungsi (Skripsi). Denpasar: Fakultas Sastra Universitas Udayana.

Subadio, Haryati. 1985. Jnanasiddhanta. Jakarta: Djambatan.

Subagiasta, I Ketut. 2007. Etika Pendidikan Agama Hindu. Surabaya: Paramita. 